\title{
Experimental study on the axial crushing behaviour of pultruded composite tubes
}

\author{
Sivakumar PALANIVELU ${ }^{1 *}$, Wim VAN PAEPEGEM ${ }^{1}$, Joris DEGRIECK ${ }^{1}$, Johan VAN \\ ACKEREN $^{2}$, Dimitrios KAKOGIANNIS ${ }^{2}$, Danny VAN HEMELRIJCK ${ }^{2}$, Jan WASTIELS ${ }^{2}$, \\ John VANTOMME ${ }^{3}$ \\ ${ }^{1}$ Department of Materials Science and Engineering, Ghent University, Sint-Pietersnieuwstraat \\ 41, 9000 Gent, Belgium \\ ${ }^{2}$ Department of Mechanics of Materials and Constructions, Vrije Universiteit Brussel, \\ Pleinlaan 2 B-1050 Brussels, Belgium \\ ${ }^{3}$ Royal Military Academy, Civil and Materials Engineering Department, Building G, Level 0, \\ 8 Av. Hobbema B-1000, Brussels, Belgium
}

\begin{abstract}
This paper presents the experimental investigation on the progressive deformation behaviour of uni-directional pultruded composite tubes subjected to an axial impact load. Pultruded square and circular profiles with glass-polyester and glass-vinylester combinations were used for this study. Two types of triggering profiles were incorporated to investigate the effect of triggering on the energy absorption. All above combinations were investigated for three different impact velocities (9.3, 12.4 and $14 \mathrm{~m} / \mathrm{s})$. The crushing peak and mean load characteristics of the composite tubes with different triggering profiles and their progressive failure modes are presented. To measure the impact velocity and the impact force, a contactless method using digital image correlation technique was adopted. The effects of the geometry profile, triggering, strain rate and the type of resin on energy absorption of the composite tubes were studied in detail.
\end{abstract}

KEYWORDS: Specific energy absorption; Triggering mechanism; Crushing; Progressive failure; Composite tubes

\section{Introduction}

A great deal of research and development has been carried out in the past decades to design safer automobiles. Out of the factors considered for safety criteria, the crashworthiness has attracted significant attention due to its multiple functions. The functions of the crashworthiness structures are to (i) absorb energy, (ii) keep the occupant compartments intact and (iii) ensure tolerable deceleration levels for driver and passengers during the crash event. To meet the above functions, the automobile industry is focused on the design architecture and materials used to produce crashworthiness. As a result, different forms of the energy absorbers [1,2] and combinations of high strength metal alloys are used for crashworthiness structures. The focus on new innovative materials which yield superior strength to weight ratio [3] has been increased in order to meet the future stringent crashworthiness norms and to enhance the fuel economy target.

On the other hand, there is a considerable amount of experiments [4-7] conducted on composite material to assess the energy absorption. It is a well-known fact that one can

* Sivakumar Palanivelu, Tel: +32-(0)9-264.33.15, Fax: +32-(0)9-264.35.87

Email: Sivakumar.Palanivelu@UGent.be 
achieve a higher energy absorption compared to metal alloys with the proper construction and architecture of composite structures. Moreover, composites have a relative advantage in terms of the specific energy absorption, ease of manufacture and maintenance. The effect of composite specimen dimensions and its geometry on the energy absorption were studied in $[8,9]$. However, the energy absorption characteristics are not only depending on the shape of the specimens and its dimensions [5]. Various variables control the energy absorption of the composite structures. The progressive crushing process which yields higher energy absorption depends on the mechanical properties of the fibre and the resin, fibre and resin volume fractions, laminate stacking sequence, fibre orientation and the geometry of the tube [5]. To produce a significant deceleration during the crash event, the failed tubes exhibit delamination, bending, axial cracking and fibre fracturing modes [10].

To achieve the above said failure modes and to reduce the peak crush load, an initiator for the stable progressive crushing is very important. Normally these initiators are known as "triggering" mechanisms. Many researchers [5, 8, 9, 11-13] employed edge chamfering of the structures as triggering mechanism. A few studies have been conducted with square tubes and "I" sectional tubes to study the effect of triggering on energy absorption [14, 15]. However, the effect of triggering mechanisms on the energy absorption of circular tubes is yet to be demonstrated. Mamalis et al. reported $[4,16]$ that square and rectangular cross sectional tubes have 0.8 and 0.5 times the specific energy absorption of circular specimens. The reason for the lower energy absorption of square rectangular cross sectional tubes is due to the higher stress concentration forming axial cracks only at the corners of the tube. Hence, it is worth investigating the role of different triggering mechanisms on energy absorption of uniform and non-uniform profiles such as circular and square cross sectional tubes.

A large number of static crushing investigations has been carried out to study the energy absorption characteristics of composite tubes. The advantage of this method is the very slow speed of the crushing process which helps to capture the deformation behaviour of composite tubes. However, most of the practical applications are dynamic in nature. The dynamic study of composite materials needs considerable instrumentation and infrastructure. Hamada et al. [17] reported that the energy absorption of the same composite tube was less in the case of dynamic load compared to static. Farley et al. [18] investigated the effect of strain rate on the energy absorption using carbon-epoxy and aramid-epoxy tubes. They reported that the resin stiffness and failure strain can be a function of strain rate. Hence, the major energy absorption associated with the interlaminar crack growth may be considered as a function of crushing speed. So, the investigation of the effect of strain rate on energy absorption of other fibre and resin types is necessary for high impact loading applications.

Ramakrishna [5] compared the energy absorption characteristics of thermoset (carbon-epoxy) and thermoplastic (carbon- PEEK) matrices. He concluded that the energy absorption of a resin depends on the interlaminar fracture toughness and its failure strain. Polyester resins are widely used in most applications due to their high performance to cost ratio. Vinylester resins are gaining popularity as they have better adhesion and fatigue properties than polyester whilst costing less than epoxy. Moreover vinylester [19] has higher strain to failure than polyester. Due to above facts, the two resins, polyester and vinylester were chosen for our study.

Many studies [6, 20] demonstrated that fibre orientation along the axis of the tube absorbed more energy than other orientations. In connection with that, pultruded tubes were chosen for this study. Square tubes made up of glass-polyester and circular tubes with glass-

* Sivakumar Palanivelu, Tel: +32-(0)9-264.33.15, Fax: +32-(0)9-264.35.87

Email: Sivakumar.Palanivelu@UGent.be 
polyester and vinylester were considered for our investigation. The effect of the geometry profile, triggering mechanism, strain rate and the type of resin on the energy absorption was studied experimentally.

\section{Materials and experimental methods}

\subsection{Composite tubes}

All the tubes used for the tests were manufactured by a pultrusion process $(\mathrm{M} / \mathrm{s}$ EXEL, Belgium). The tube laminates were made with continuous $0^{\circ}$ orientation fibres. To get a better surface finish, the outer and inner layers were made up of random short glass fibres with approximate thickness of $0.1-0.2 \mathrm{~mm}$. The architectural construction of the circular pultruded profiles used for our study is schematically shown in Figure 1. Six different tube combinations SP1, SP2, CP1, CP2, CV1 and CV2 were studied experimentally. The SP1 refers to the square cross sectional glass-polyester pultruded tube with triggering type 1 . The SP2 refers to the square cross sectional glass-polyester pultruded tube with triggering type 2 . The CP1 and CP2 refer to the circular cross sectional glass-polyester tube with triggering type 1 and 2 respectively. Similarly, the CV1 and CV2 refer to the circular cross sectional glass-vinylester tube with triggering type 1 and 2 respectively. The triggering type 1 is $45^{\circ}$ chamfering around the edges of the tubes and the type 2 is a tulip pattern with an included angle of $60^{\circ}$ between the edges. The details of the two triggering profiles for circular tubes are shown in Figure 2. The motivation to choose these types was: for type 1 profile the initial contact of the impactor will be uniform along the circumference of the tube at the time of impact, whereas in the case of type 2 the contact will take place at the sharp edges of the specimen. The first mechanism would enhance uniform circumferential interlaminar cracks causing uniform delamination, whereas in the case of triggering type 2, the initial cracks develop at the sharp edges of the tube which make first contact with the impactor. The circular and square test specimens with two types of triggering are shown in Figure 3.

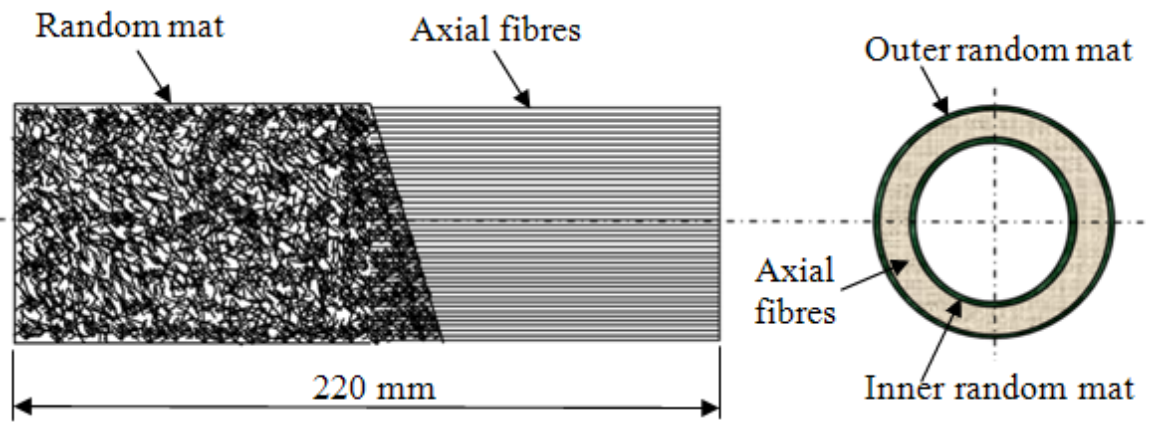

Figure 1: Architectural construction of the pultruded tubes.

* Sivakumar Palanivelu, Tel: +32-(0)9-264.33.15, Fax: +32-(0)9-264.35.87

Email: Sivakumar.Palanivelu@UGent.be 

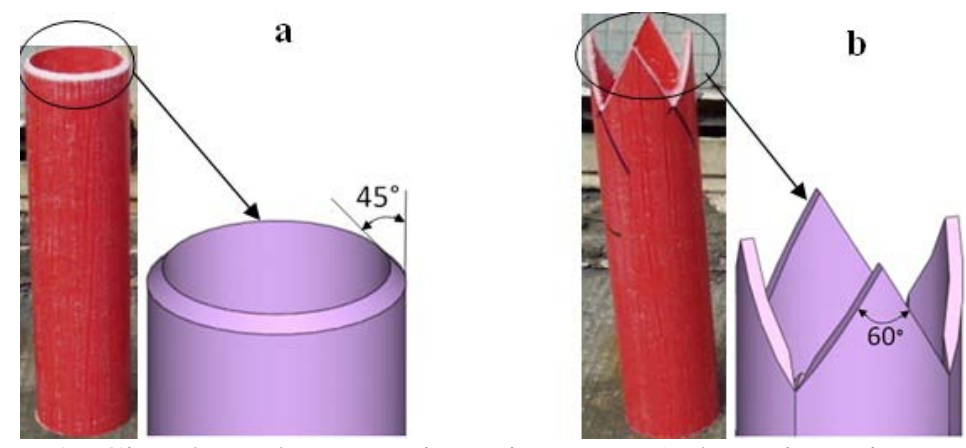

Figure 2: Circular tube (a) Triggering type 1 (b) Triggering type 2.
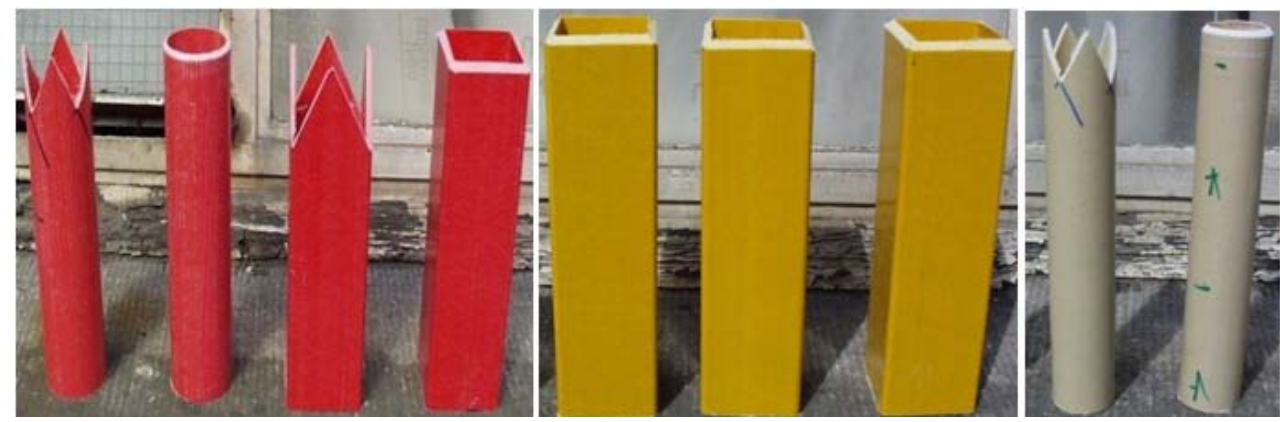

Figure 3: Test tube specimens.

Studies conducted on the progressive crushing of circular cross-sectional tubes proved that tubes having a $\mathrm{t} / \mathrm{D}$ ratio less than 0.015 will fail catastrophically $(\mathrm{t}$ - thickness of the tube; $\mathrm{D}$ - diameter of the tube) [21]. However, tubes with a t/D ratio in the range 0.015 to 0.25 will crush progressively. So, the t/D ratio of the circular tubes was chosen as 0.06 and 0.07 for CP and CV series respectively. For SP series, a t/W ratio of 0.075 (W- width of the tube) was chosen. The tolerances in the tube dimensions (outer width, outer diameter and thickness) were checked. The standard deviation of outer width and thickness of SP series and outer diameter and thickness of CP and CV series were 0.05, 0.05; 0.09, 0.12; $0.05 \mathrm{~mm}$ and $0.04 \mathrm{~mm}$ respectively.

To achieve the progressive failure of the composite tubes, the linear density (mass per unit length) of the tube was chosen as recommended in [22]. The resin and the fibre volume fraction were calculated based on ASTM D 2584. The details of the tube geometry, fibre, resin, tube dimensions, linear density and the corresponding volume fraction are mentioned in Table 1 and 2.

Table 1: Dimensional and material details of the tube series.

\begin{tabular}{|c|c|c|c|c|c|c|c|}
\hline S.No & $\begin{array}{c}\text { Tube } \\
\text { series }\end{array}$ & $\begin{array}{c}\text { Cross } \\
\text { section }\end{array}$ & Fibre & Resin & $\begin{array}{c}\text { Dimensions } \\
(\mathrm{mm})\end{array}$ & $\begin{array}{c}\rho_{\text {linear }} \\
(\mathrm{g} / \mathrm{mm})\end{array}$ & Volume fraction \\
\hline 1. & $\mathrm{SP}$ & Square & Glass & Polyester & $\begin{array}{c}\text { Outer width }=60 \\
\text { Thickness }=4.5 \\
\text { Length }=220\end{array}$ & 1.81 & $\begin{array}{c}\text { Resin }\left(\mathrm{V}_{\mathrm{m}}\right)=49.2 \% \\
\text { Fibre }\left(\mathrm{V}_{\mathrm{f}}\right)=50.8 \%\end{array}$ \\
\hline 2. & $\mathrm{CP}$ & Circular & Glass & Polyester & $\begin{array}{c}\text { Outer diameter }=50 \\
\text { Thickness }=3 \\
\text { Length }=220\end{array}$ & 0.66 & $\begin{array}{c}\text { Resin }\left(\mathrm{V}_{\mathrm{m}}\right)=51.7 \% \\
\text { Fibre }\left(\mathrm{V}_{\mathrm{f}}\right)=48.3 \%\end{array}$ \\
\hline 3. & $\mathrm{CV}$ & Circular & Glass & Vinylester & $\begin{array}{c}\text { Outer diameter }=38 \\
\text { Thickness }=3 \\
\text { Length }=220\end{array}$ & 0.60 & $\begin{array}{c}\text { Resin }\left(\mathrm{V}_{\mathrm{m}}\right)=49.7 \% \\
\text { Fibre }\left(\mathrm{V}_{\mathrm{f}}\right)=50.3 \%\end{array}$ \\
\hline
\end{tabular}

Table 2: Break-up fibre volume fraction. 


\begin{tabular}{|c|c|c|c|c|}
\hline S.No & $\begin{array}{c}\text { Tube } \\
\text { series }\end{array}$ & $\begin{array}{c}\text { Total volume fraction } \\
\text { of fibre }\end{array}$ & $\begin{array}{c}\text { Volume fraction of 0 } \\
\text { up lay- }\end{array}$ & $\begin{array}{c}\text { Volume fraction of } \\
\text { random mat }\end{array}$ \\
\hline 1. & SP & $50.8 \%$ & $40.3 \%$ & $10.5 \%$ \\
\hline 2. & CP & $48.3 \%$ & $36.2 \%$ & $12.1 \%$ \\
\hline 3. & CV & $50.4 \%$ & $41.4 \%$ & $9.0 \%$ \\
\hline
\end{tabular}

\subsection{Experimental set-up}

All tests have been performed with the large scale drop weight test facility shown in Figures 4 and 5. The main horizontal supporting structure is attached to a vertical wall. The horizontal supporting structure carries the vertical guides along which the impactor slides. An impactor mass of $68.85 \mathrm{~kg}$ was used for all tests. The bottom surface of the impactor was made flat to affix the composite test specimen and to ensure the co-axial condition between the test specimen and the impactor (Figure 5). A scale was fixed parallel to the guiding rail to measure the drop height. The maximum drop height of the experimental setup is $12 \mathrm{~m}$. However, for this experiment the impact height was limited to $10 \mathrm{~m}$. The bottom of the vertical sliding support is fixed to a $20 \mathrm{~mm}$ thick steel plate to withstand the total impact force during the impact test. The impact base plate setup was placed over a massive concrete base.

\subsection{Data acquisition system}

The system was equipped with a high speed camera (Photron APX RS 250K) with maximum frame rate of 250,000 fps (Figure 6); this was connected to a computer which records the images at specified times during the impact event. The tracking area by the camera covered the entire impact base. A special metal - halide lamp was used to maintain the light intensity at the area of impact.

To capture the crash event of the composite tubes, a frame rate of $2000 \mathrm{fps}$ was chosen. The corresponding pixel resolution of the screen was 1024 X 1024, with a remaining resolution of 384 X 400 for the area of impact. Markers were placed on the impactor as well as on the test specimen for digital image tracking. About half a meter height was covered by the focus lens of the high speed camera from the base of the impact system. The position of the impactor was recorded at every instance of impact time. From these data, the corresponding velocities were calculated. Due to the clearance between the impactor guiding system and the impactor, a small change in the horizontal velocity was noticed. However, compared to the magnitude of the vertical velocity it was negligible.

* Sivakumar Palanivelu, Tel: +32-(0)9-264.33.15, Fax: +32-(0)9-264.35.87

Email: Sivakumar.Palanivelu@UGent.be 


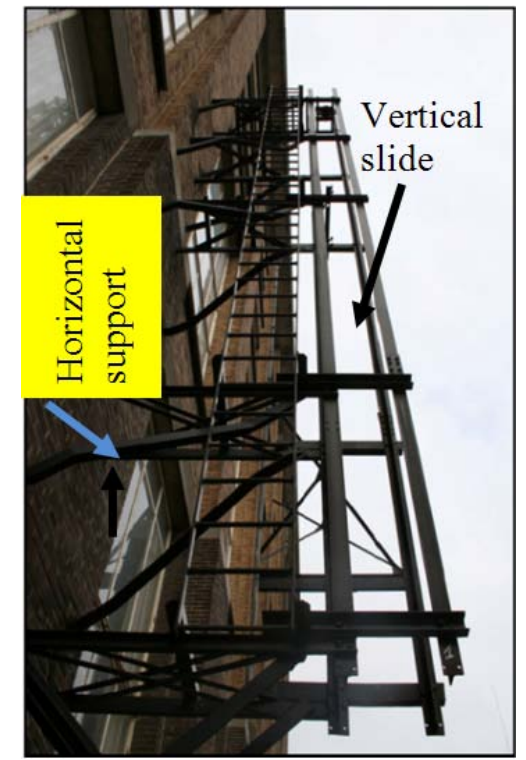

Figure 4: Experimental set-up.

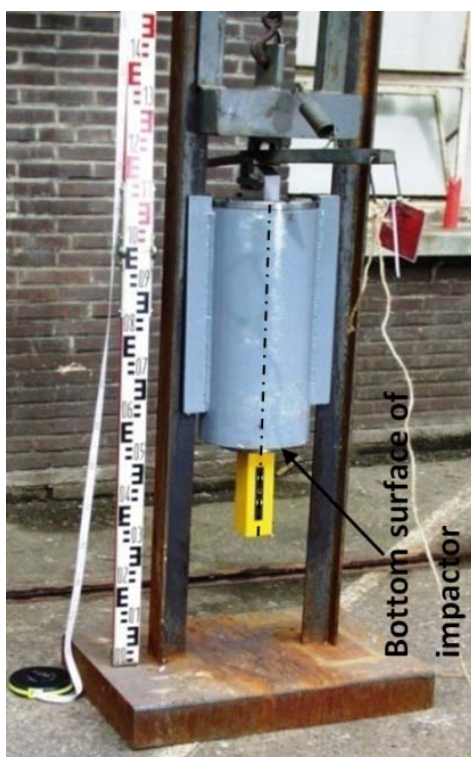

Figure 5: Impactor.

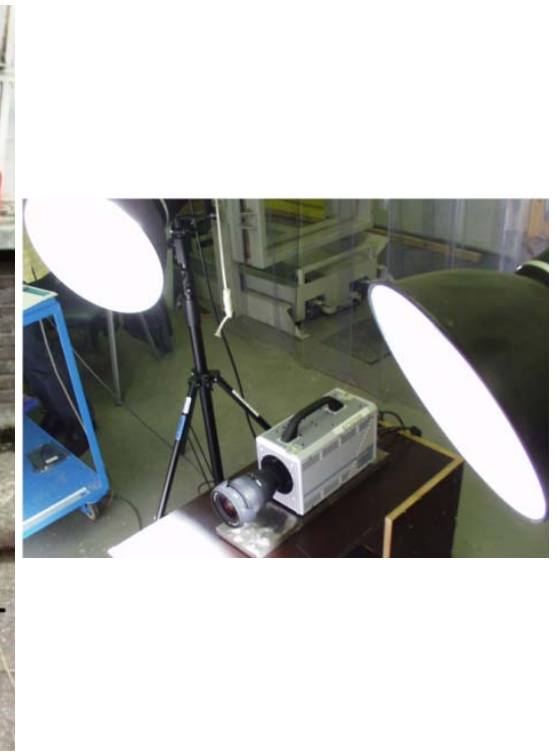

Figure 6: High speed camera.

\subsection{Data processing using digital image correlation technique}

Traditionally, many contact sensors have been employed to collect the data during an impact test. Often, to select the appropriate data acquisition equipments, prior knowledge of the magnitude of the peak crushing force and the duration of the crash event is important. However, this is not an easy task. Any improper selection would lead to loss of sensors and equipment. Hence, a contact-less method is an interesting alternative to collect the data during such high dynamic events. In this paper, the digital image correlation technique is used to measure the impact velocity and the corresponding impact force. From the data obtained from the high speed images, the deformation length of the tube (equivalent to the displacement of the impactor) with respect to time was calculated using the digital image correlation commercial code Vic-2D. Subsequently, the above data was differentiated to get the impact velocity and the corresponding deceleration of the impactor for every time interval. It was assumed that the deceleration of the impactor was constant during a time interval. Based on this assumption, the reaction force of the tube was calculated by the multiplication of the mass of the impactor and the deceleration during the time interval [23]. Further details for this method (DIC) of calculation can be found in [24].

\section{Experimental results and discussions}

\subsection{Failure pattern}

The progressive failure pattern of different types of composite tubes was investigated with different impact velocities. Each set of composite tubes consists of square (SP1 and SP2) and circular tubes (CP1, CP2, CV1 and CV2). They were tested with different drop heights which correspond to 9.3, 12.4 and $14 \mathrm{~m} / \mathrm{s}$ initial impact velocities. Sample of a circular composite tube which has undergone the different phases of deformation are shown in Figure 7. All the tubes exhibited the progressive crushing failure modes.

* Sivakumar Palanivelu, Tel: +32-(0)9-264.33.15, Fax: +32-(0)9-264.35.87

Email: Sivakumar.Palanivelu@UGent.be 


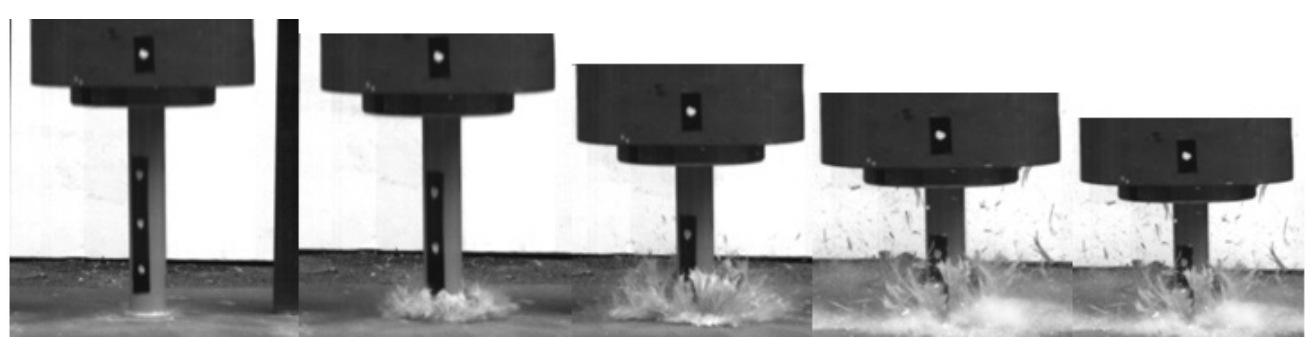

Figure 7: Different phases of circular tube (CV1) crushing.

\subsubsection{Square tubes}

For both types of square tubes (SP1 and SP2), after the circumferential delamination due to stress concentration, primary longitudinal cracks were developed along the corners. As a result, each side of the tube has split into petals moving inwards and outwards. The major impact energy of both types of tubes was exhibited by lamina bending followed by the breakage of resin bonds. The separation of plies from each other was directly proportional to the number of interlaminar cracks which developed during the impact process. The complete surface delamination of inner and outer random fibre mat was observed from the core fibres. The de-cohesion of outer and inner skin is due to the uneven distribution of the bonding strength along the thickness of the tube. The lamina of each face of the square tube acted as a cantilever beam, which absorbed a considerable amount of energy by its bending mode. During the crash event, the bending angle of each petal was observed 90 for all square tubes. However, due to the high stiffness of each petal the angle was gradually reduced when the impact force magnitude reached to zero (Figure 8(a) and (b)). This mode was observed to be different from the previously reported modes [25] where all the petals deformed permanently for $90^{\circ}$. However, the inner laminae have undergone permanent bending as well as tearing mode (Figure 8(a) and (b)). Unlike triggering type 1, triggering type 2 exhibited permanent bending of the laminae due to their lower stiffness. This can be clearly seen in Figures 9(a) and (b).
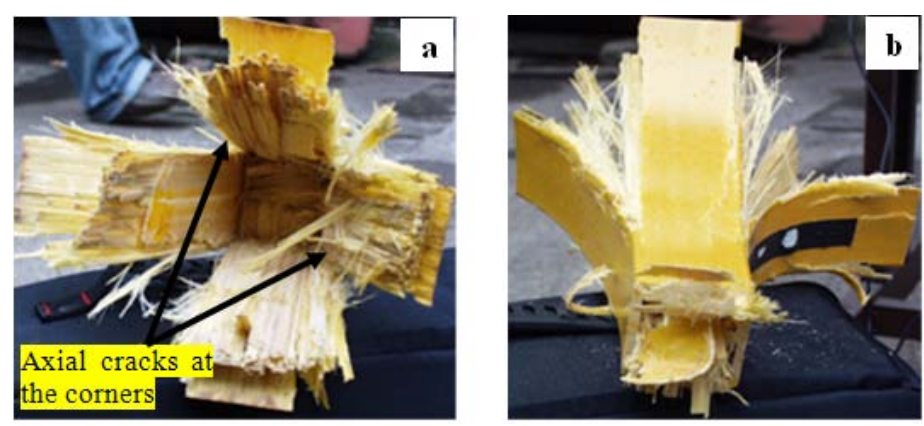

Figure 8 (a) and (b): Failure patterns of SP1 tube series.
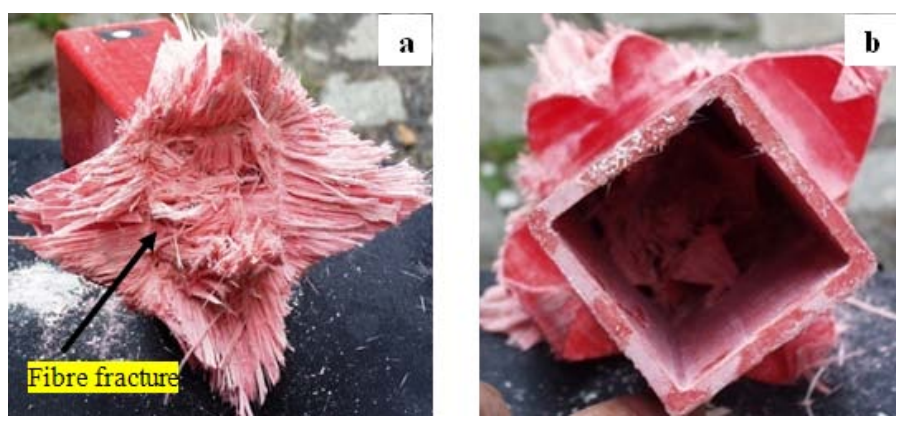

Figure 9 (a) and (b): Failure patterns of SP2 tube series.

* Sivakumar Palanivelu, Tel: +32-(0)9-264.33.15, Fax: +32-(0)9-264.35.87

Email: Sivakumar.Palanivelu@UGent.be 


\subsubsection{Circular tubes}

Similar to square tubes, in all varieties of circular tubes (CP1, CP2, CV1 and CV2) the inner and outer petals were formed due to the circumferential delamination and, consequently, axial cracks were formed parallel to the axis of the tube. The uniform geometry of the circular tube facilitated to form more axial cracks and, thus, more petals were formed. The major amount of impact energy was absorbed due to the increasing number of longitudinal cracks and subsequent bending of the laminates [10]. This phenomenon was clear in all cases in which the specific energy absorption of the circular tube was more than the square tube. Unlike the square tubes, irrespective of the triggering and fibre volume fraction, the bending angles of the laminates were greater than or equal to $90^{\circ}$ (Figure 10 and 11). For all tube series (SP1, SP2, CP1, CP2, CV1 and CV2) the bending of the inner petals reduced the acceleration of the impactor considerably due to the blockage of material within the profile.
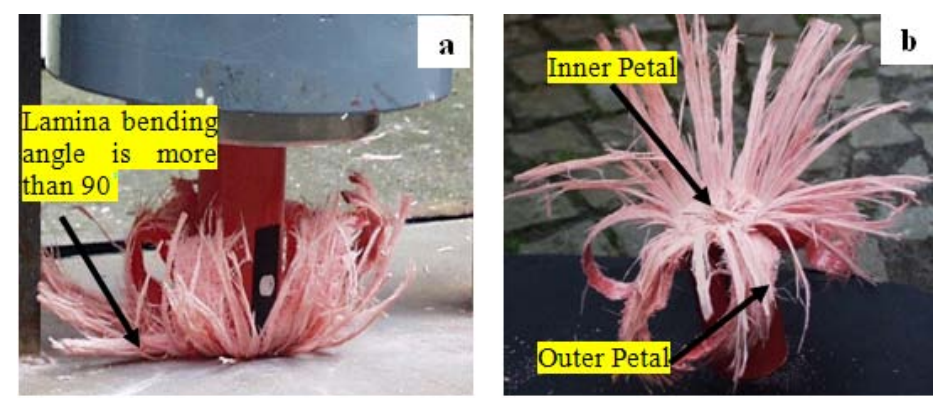

Figure 10 (a) and (b): Failure patterns of CP1 and CP2 series.
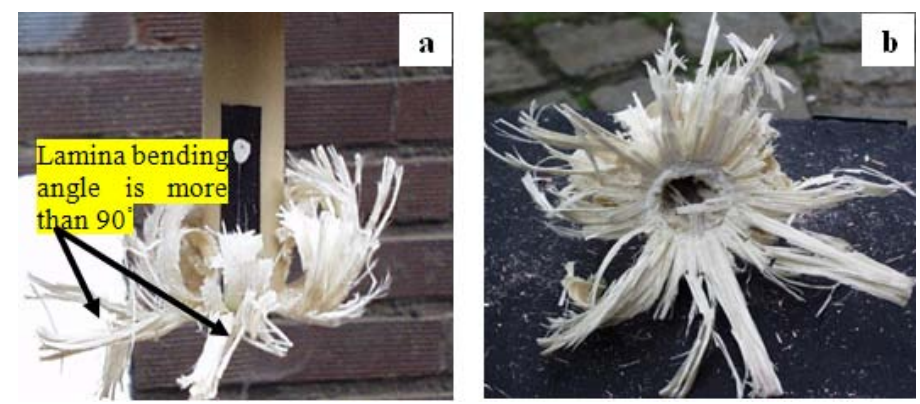

Figure 11 (a) and (b): Failure patterns of CV1 and CV2 series.

\subsubsection{Study of longitudinal cuts}

After the impact testing, all samples were longitudinally cut to carry out a visual inspection of the crushed zone. The cut section of all tube series gave clear evidence that the major delamination took place at the mid thickness of the tube. A similar result was reported in $[10,26]$. Other than the axial cracks, a smaller number of trans-laminar cracks (cracks which are perpendicular to the direction of the fibre orientation) were noticed for the SP series. These axial and trans-laminar cracks were longer in length. In contrast, for CP and $\mathrm{CV}$ series, a larger number of axial and trans-laminar cracks were observed, however the length of the axial and trans-laminar cracks were controlled by the uniform geometry of the circular tubes. As a result, each laminate has split into a larger number of thinner layers. Due to the controlled axial trans-laminar cracks, more fibres of the CP and CV series have undergone fracture at the fixed end of the cantilever portion. In the case of SP series, less fibres had undergone fracturing due to the larger radius of bending. This phenomenon can be clearly seen from the difference between the amount of fibres and their angle of bending

* Sivakumar Palanivelu, Tel: +32-(0)9-264.33.15, Fax: +32-(0)9-264.35.87

Email: Sivakumar.Palanivelu@UGent.be 
between square and circular tubes (Figure 12 and 13). Unlike SP and CP series, in the case of $\mathrm{CV}$ series there was no de-cohesion of the random mat from the core fibres noticed. The better adhesion property of vinylester resin attributed to the increasing uniform strength along the thickness of the tube.
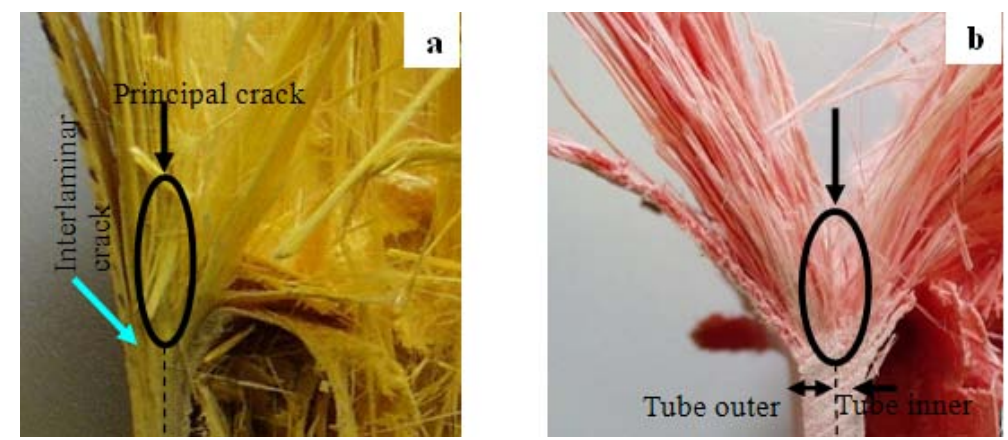

Figure 12: (a) Longitudinal cut section of SP1 tube (b) Longitudinal cut section of SP2 tube.
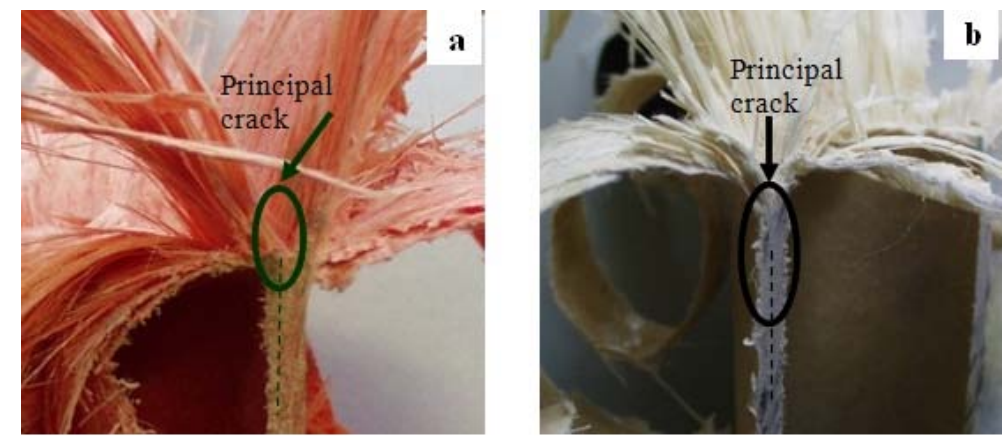

Figure 13: (a) Longitudinal cut section of CP tube (b) Longitudinal cut section of CV tube.

\subsection{Force-deformation curves}

The force-deformation curves of the tube series SP1, CP1 and CV1 for different initial impact velocities are shown in Figures 14 to 16. In all series, the force-deformation curves followed three phases. The first phase was the sudden increase in peak load at the initial stage of compression. During this stage, the triggering length of the tube was completely crushed and was followed by the start of the circumferential delamination. The area under the peak load in the force-deformation curve corresponds to the total energy spent on the initial circumferential delamination of the composite tube. After the circumferential delamination the peak load decreased abruptly. This corresponds to the second stage of the crushing. At the end of this second stage a significant amount of energy was consumed by bending of the petals followed by the shear deformation of plies that led to fibre fracture at the fixed end of the petal. The chronological order of delamination, axial cracks, bending of petals and, due to that, the shear fracture of the fibre continued for the subsequent stages of crushing. Due to the above failure modes, the crushing load of the tube oscillated around a mean value. This was the third stage of crushing. The similar trend of all three stages was observed in the case of triggering type 2 also. However, due to the triggering tulips, the time to reach the major delamination was different than for type 1 series and a smaller slope of the peak load was observed. The magnitude of the peak crushing load and the corresponding mean crushing load are given in Table 3. The mean crushing load of all tube series was calculated based on Equation 1.

* Sivakumar Palanivelu, Tel: +32-(0)9-264.33.15, Fax: +32-(0)9-264.35.87

Email: Sivakumar.Palanivelu@UGent.be 


$$
P_{\text {mean }}=\frac{\int_{0}^{l_{\max }} p(l) d l}{l_{\max }}(\mathrm{kN})
$$

where $\mathrm{P}(\mathrm{l})$ is the instantaneous crushing load corresponding to the instantaneous crushing deformation length $\mathrm{dl}$. $\mathrm{l}_{\max }$ is the maximum or total deformation length. The ratio of the mean crush load to the peak crush load, which indicates the efficiency of the crushing $\left(\eta_{\mathrm{c}}\right)$, is also given in Table 3 . In the case of the SP1 and CP1 series, the tests at three different velocities (9.3, 12.4 and $14 \mathrm{~m} / \mathrm{s})$ exhibited a very similar peak crushing load. However, in the case of the CV1 series, a minor increase in peak load was observed with increasing impact velocity. The CP1 and CV1 series exhibited approximately the same mean crush load for all three impact velocities. As a result, the crush efficiency of these tube series remained approximately constant for all impact velocities. In the case of SP1 the mean load of crushing was increased with increasing impact velocity and, consequently, the crush efficiency was also increased. The increased mean crush load may be due to the blockage of the material at the inner profile of the tube.

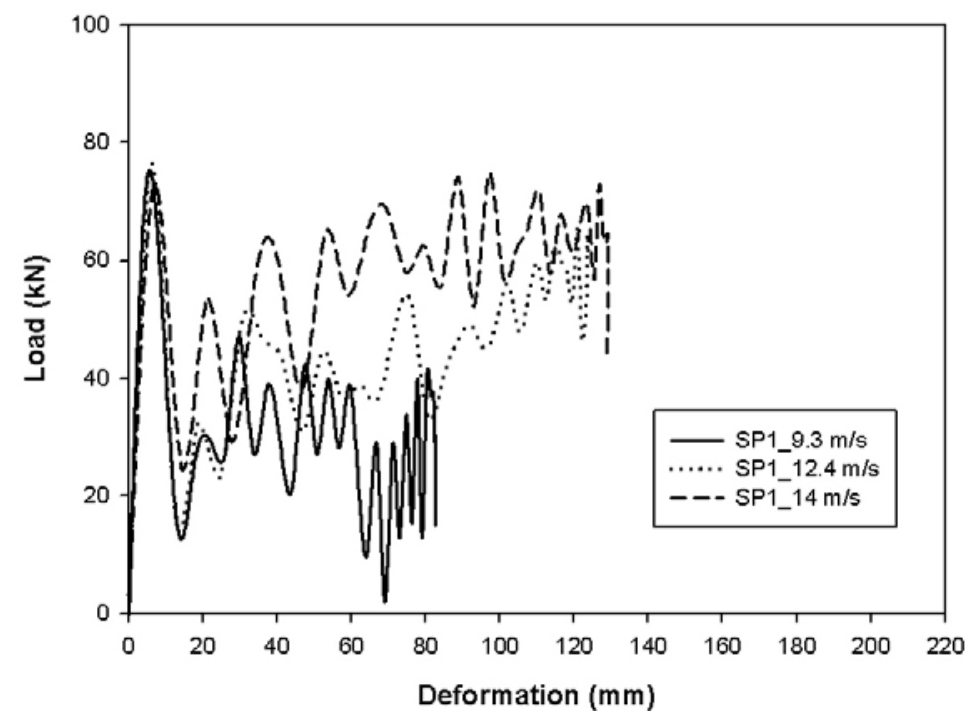

Figure 14: Force-deformation curves for SP1 series.

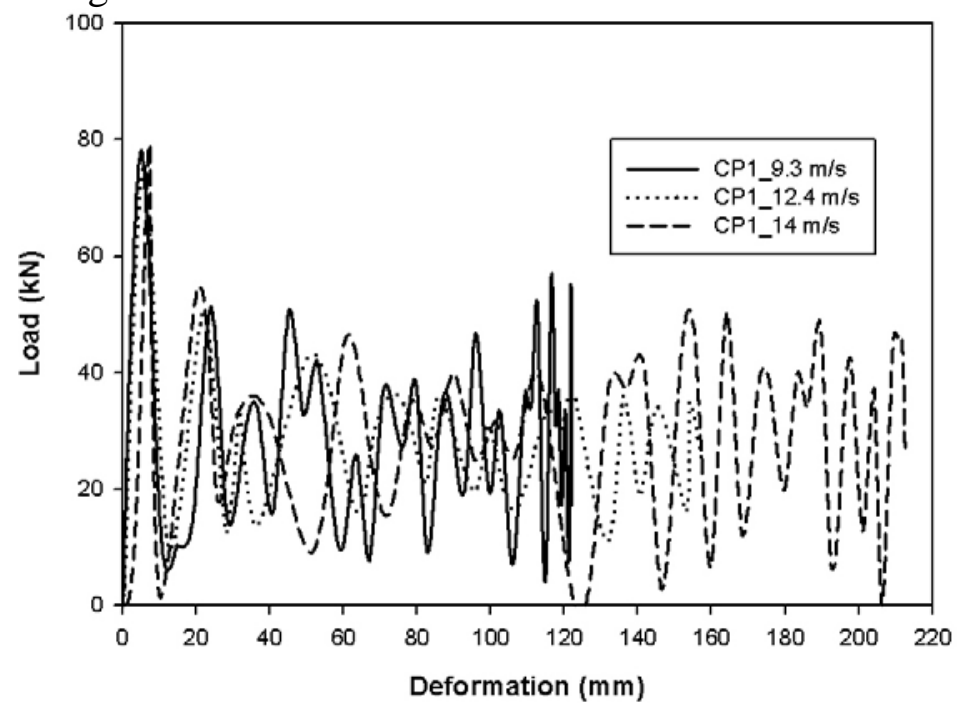

Figure 15: Force-deformation curves for CP1 series. 


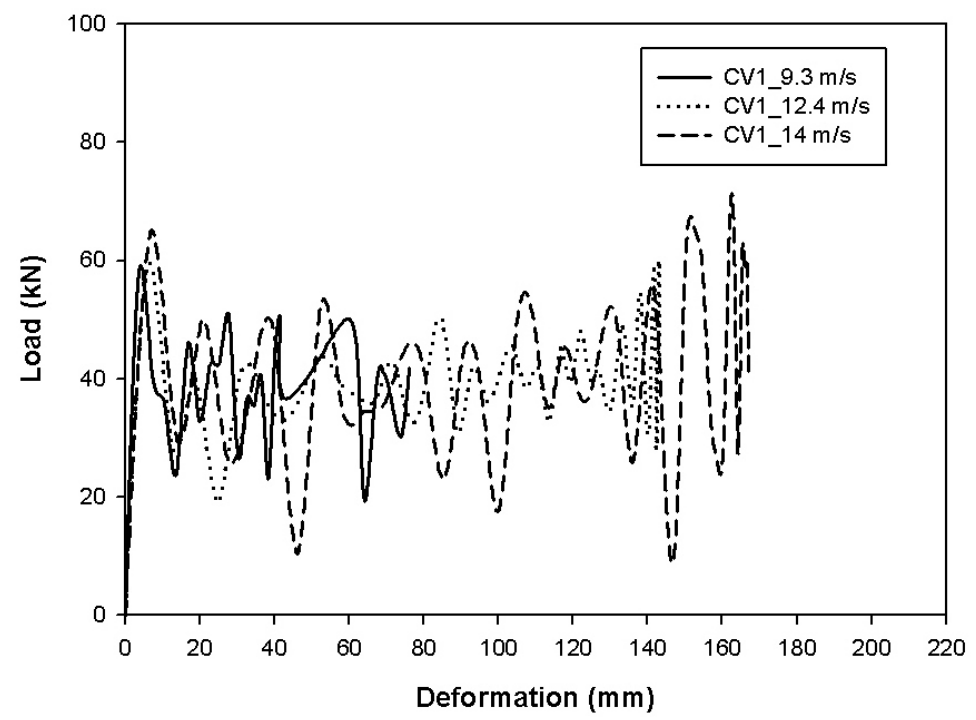

Figure 16: Force-deformation curves for CV1 series.

Table 3: Summary of crushing loads and absorbed energy.

\begin{tabular}{|c|c|c|c|c|c|c|c|c|c|c|c|c|}
\hline \multirow{3}{*}{$\begin{array}{c}\text { Tube } \\
\text { series }\end{array}$} & \multicolumn{4}{|c|}{ Impact velocity 9.3 m/s } & \multicolumn{4}{c|}{ Impact velocity $12.4 \mathrm{~m} / \mathrm{s}$} & \multicolumn{3}{c|}{ Impact velocity $14 \mathrm{~m} / \mathrm{s}$} \\
& $\begin{array}{c}\text { Peak } \\
\text { load } \\
(\mathrm{kN})\end{array}$ & $\begin{array}{c}\text { Mean } \\
\text { load } \\
(\mathrm{kN})\end{array}$ & $\begin{array}{c}\text { Absorbed } \\
\text { energy } \\
(\mathrm{kJ})\end{array}$ & $\begin{array}{c}\eta_{\mathrm{c}} \\
(\%)\end{array}$ & $\begin{array}{c}\text { Peak } \\
\text { load } \\
(\mathrm{kN})\end{array}$ & $\begin{array}{c}\text { Mean } \\
\text { load } \\
(\mathrm{kN})\end{array}$ & $\begin{array}{c}\text { Absorbed } \\
\text { energy } \\
(\mathrm{kJ})\end{array}$ & $\begin{array}{c}\eta_{\mathrm{c}} \\
(\%)\end{array}$ & $\begin{array}{c}\text { Peak } \\
\text { load } \\
(\mathrm{kN})\end{array}$ & $\begin{array}{c}\text { Mean } \\
\text { load } \\
(\mathrm{kN})\end{array}$ & $\begin{array}{c}\text { Absorbed } \\
\text { energy } \\
(\mathrm{kJ})\end{array}$ & $\begin{array}{c}\eta_{\mathrm{c}} \\
(\%)\end{array}$ \\
\hline SP1 & 73 & 31.01 & 2.563 & 42.5 & 77 & 43.18 & 5.341 & 56.4 & 73 & 55.95 & 7.218 & 76.5 \\
\hline SP2 & 73 & 37.20 & 2.680 & 51.9 & - & - & - & & - & - & - & - \\
\hline CP1 & 78 & 28.34 & 3.462 & 36.4 & 76 & 28.10 & 4.455 & 37.2 & 79 & 28.3 & 6.029 & 35.8 \\
\hline CP2 & 69 & 26.05 & 3.470 & 37.8 & - & - & - & - & - & - & - & - \\
\hline CV1 & 59 & 38.66 & 2.938 & 65.5 & 60 & 38.52 & 5.508 & 64.5 & 65 & 39.01 & 6.515 & 59.8 \\
\hline CV2 & 63 & 34.62 & 3.448 & 55.3 & - & - & - & - & - & - & - & - \\
\hline
\end{tabular}

\subsubsection{Effect of triggering on peak load}

The effect of triggering on the load-deformation curve for the tube series SP, CP and CV can be clearly seen from Figures 17, 18 and 19. For SP and CV tube series, no appreciable difference in peak load was noticed between triggering type 1 and 2 . However, in the case of the CP series, due to the triggering type 2, there was a $12 \%$ reduction in peak load. In all tube series with triggering type 2 , the average slope to reach the peak load was uniform. The gradual increase in the load was due to the reduced stiffness of each tulip and, hence, less energy was required for delamination. However, in both cases the peak load occurred at a stage where the circumferential delamination took place. For the CP and CV series, a higher deformation length was noticed due to triggering type 2 . However, in the case of the SP series there was a negative effect observed and so the deformation length of triggering 1 was higher than type 2. Apart from the peak load, a significant difference in the mean crush load was noted for triggering type 2 series. Apart from the SP tube series, the mean crush load of CP2 and CV2 were smaller than CP1 and CV1. The lower mean crush load of the tube series may be due to the delayed major delamination and, subsequently, less resistance offered by the triggering tulips. The comparison of peak and mean crush load of all tube series for the initial impact velocity $9.3 \mathrm{~m} / \mathrm{s}$ is given in Table 3 . 


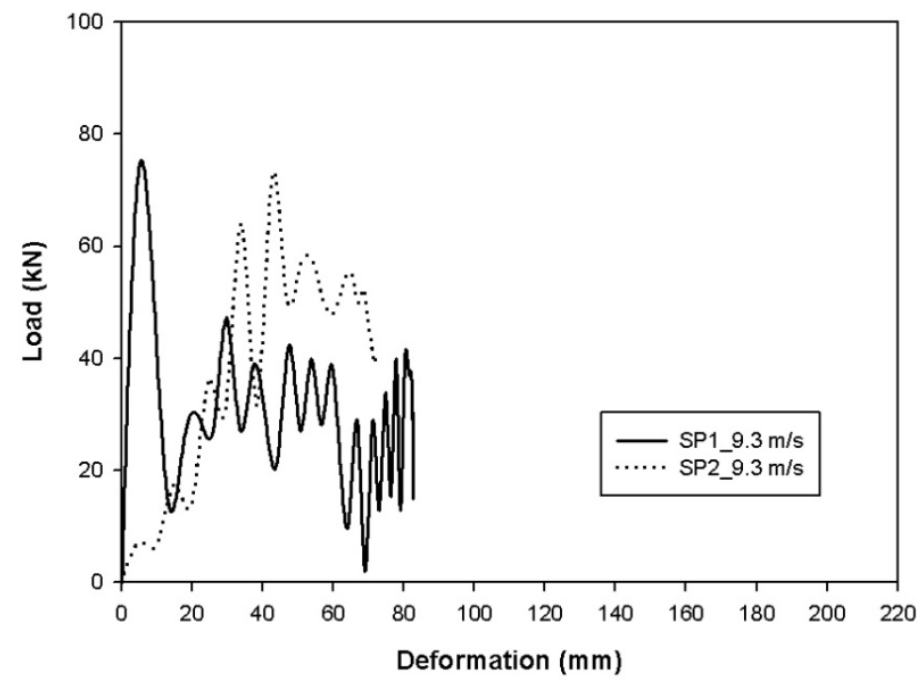

Figure 17: Comparison of SP1 and SP2 tubes.

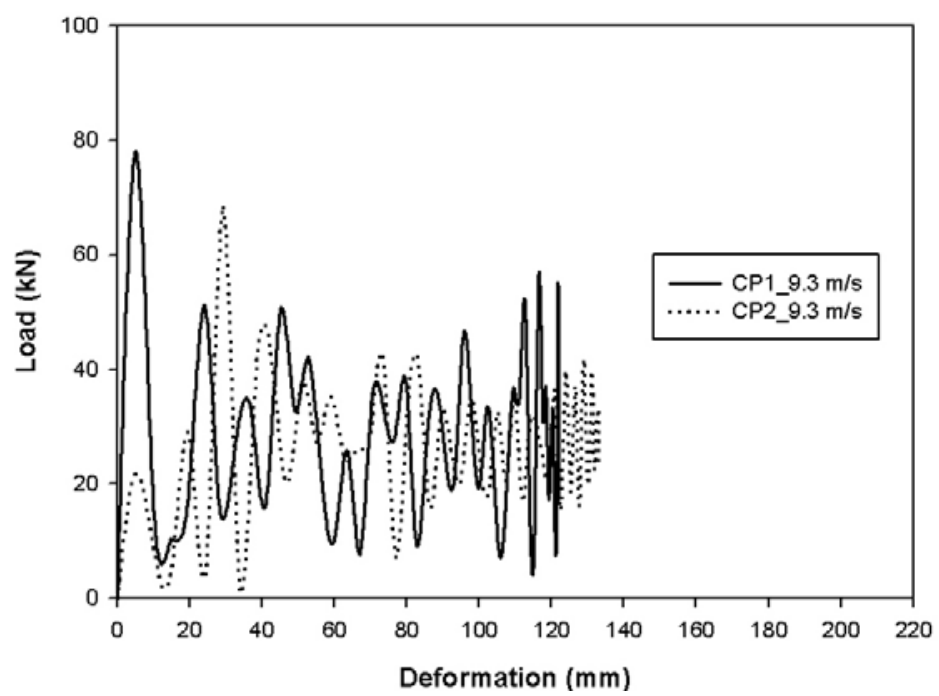

Figure 18: Comparison of CP1 and CP2 tubes.

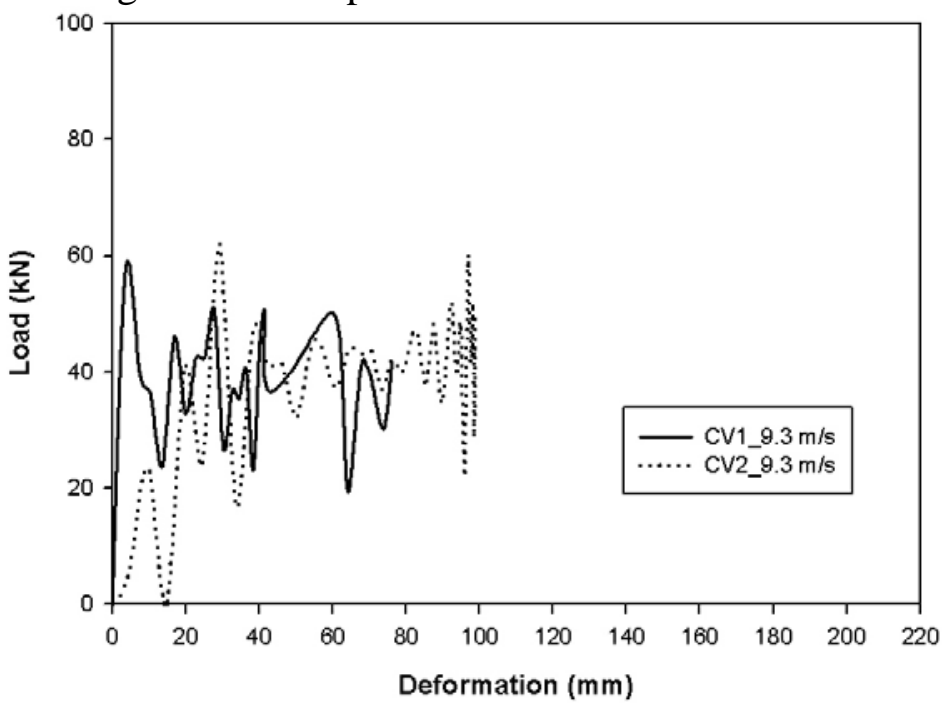

Figure 19: Comparison of CV1 and CV2 tubes. 


\subsection{Specific energy absorption}

In order to determine the deformation length of the tube series, two specimens were tested in each category. The maximum deformations of the tubes were taken into account and, thus, minimum specific energy absorption of each case was calculated. The total energy absorption $\left(E_{d}\right)$ of each case was calculated based on Equation 2 and the same is summarized in Table 3.

$$
E_{d}=\int_{0}^{l_{\max }} P(l) d l[\mathrm{~kJ}]
$$

To understand the energy absorption effectiveness of each tube, the specific energy absorption (SEA - normalized with respect to mass) was calculated based on Equation 3.

$$
\mathrm{SEA}=\frac{\int_{0}^{l_{\max }} P(l) d l}{l_{\max } .} \cdot \frac{1}{\rho} \quad(\mathrm{kJ} / \mathrm{kg})
$$

where $\rho$ is the linear density of the composite tube $(\mathrm{kg} / \mathrm{m})$.

\subsubsection{Effect of geometry and triggering on SEA}

The comparison of the specific energy absorption of the SP, CP and CV series of triggering type 1 and 2 for the initial impact velocity $9.3 \mathrm{~m} / \mathrm{s}$ is presented in Figure 20. The specific energy absorption of circular tubes (CP and CV series) in all cases is higher than the square tubes (SP series). As discussed earlier in section 3.1.2, the uniform geometry the circular tube yielded a larger number of axial cracks. These cracks attributed to a higher specific energy absorption. In case of square tubes, due to the higher stress concentration, the major axial cracks were formed at the four corners of the tube. Out of the total energy absorbed by the square tube in each category (SP1 and SP2), a significant amount of energy was absorbed by lamina bending followed by shear fracture at the fixed end of each sublaminate.

The effect of triggering on SEA is also clearly explained by Figure 20. In the case of $\mathrm{CP}$ and $\mathrm{CV}$ series, triggering type 1 absorbed more energy than triggering type 2 . This is due to the fact that, during the impact event, the controlled circumferential delamination followed by the axial cracks took place uniformly along the circumference of the tube. In the case of triggering type 2, the delamination propagated at the sharp edges of the tube. The crushing of the triggering length of the tube delayed the major circumferential delamination. Compared to triggering type 1, an approximate time delay of 2-3 milliseconds was observed in all cases of triggering type 2 . This can be noted from the shift of peak load compared to type 1 in Figure 17 to 19.

Due to the above effects, the SEA of CP2 and CV2 series are 7.4 and 9.8\% lower than CP1 and CV1 series for the case with initial impact velocity $9.3 \mathrm{~m} / \mathrm{s}$. However, in the case of square tubes the SEA was higher for triggering type 2 than for triggering type 1 . The increase in SEA of $16.5 \%$ was noticed for SP2 tubes compared to SP1 tubes. Although the delay in delamination occurred between triggering type 1 and 2, in both SP1 and SP2 series a

* Sivakumar Palanivelu, Tel: +32-(0)9-264.33.15, Fax: +32-(0)9-264.35.87

Email: Sivakumar.Palanivelu@UGent.be 
significant amount of energy was dissipated by lamina bending followed by the shear fracturing of the fibres. The stiffness of each side of the laminate of SP2 tubes was less than SP1 series. The lower stiffness of each laminate attributed to the shear fracture of fibres at the base of the tulips followed by the major delamination. Due to this effect, each laminate of SP2 series exhibited a permanent bending angle of $90^{\circ}$, whereas in the case of triggering type 1 it was approximately $45^{\circ}$.

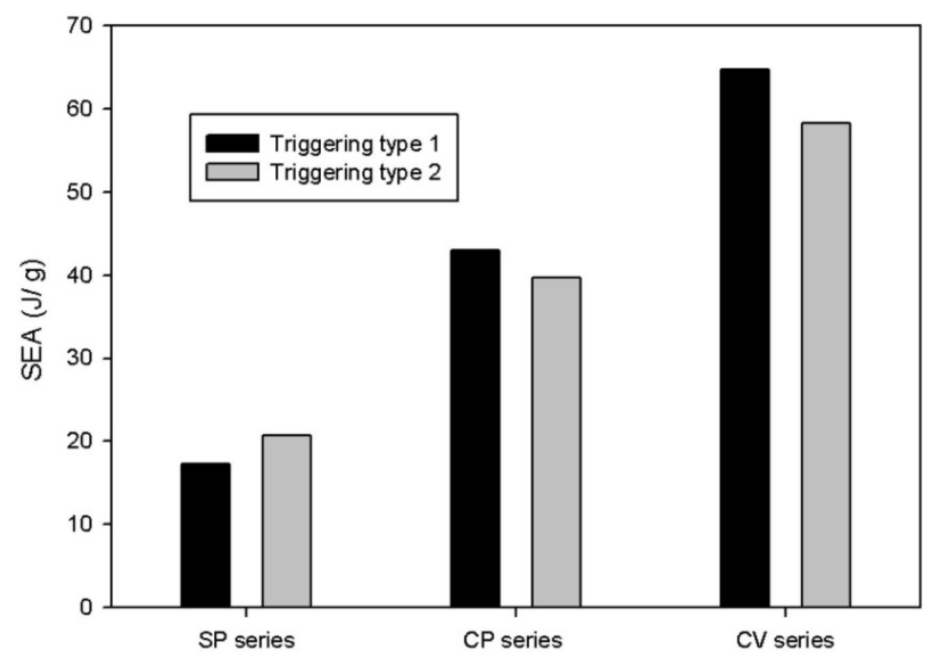

Figure 20: Effect of triggering on SEA.

\subsubsection{Effect of strain rate and resin type on SEA}

The initial study of the tubes for the impact velocity $9.3 \mathrm{~m} / \mathrm{s}$ indicated that the specific energy absorption of tube series CP1 and CV1 exhibited more SEA than type 2. Therefore, it was decided to study the strain rate effect on SEA using the type 1 series. From the experiments conducted, the SEA of each tube was calculated based on the higher deformation length of each series. From Figure 21, it can be noted that the energy absorption of SP1 tube was sensitive to the impact velocity. There was a linear increase in SEA of $26 \%$ from the lower to the higher velocity. In the case of the CP series, there was a positive dependency with respect to the strain rate; however, the difference in SEA was small. Similarly, for the $\mathrm{CV}$ series there was no appreciable increase in SEA from $9.3 \mathrm{~m} / \mathrm{s}$ to $12.4 \mathrm{~m} / \mathrm{s}$, in contrast a negative dependency was observed for $14 \mathrm{~m} / \mathrm{s}$.

The effect of resin type on SEA can be concluded from the comparison of CP and CV series. In all cases, the CV1 tubes absorbed more energy than CP1 series. This is clearly evident from the fact that the SEA of CV1 series is higher than CP1 series by $33 \%$ for initial impact velocities of 9.3 and $12.4 \mathrm{~m} / \mathrm{s}$. A difference of $27 \%$ was noted for the case of $14 \mathrm{~m} / \mathrm{s}$ impact velocity. One reason for the increase in SEA could be the higher tensile strength and modulus of the vinylester which causes better interlaminar strength. Furthermore, due to the smaller diameter of CV tubes, more blockage of material (debris) occurred at the inner wall. This phenomenon also may be attributed to an increase in SEA. 


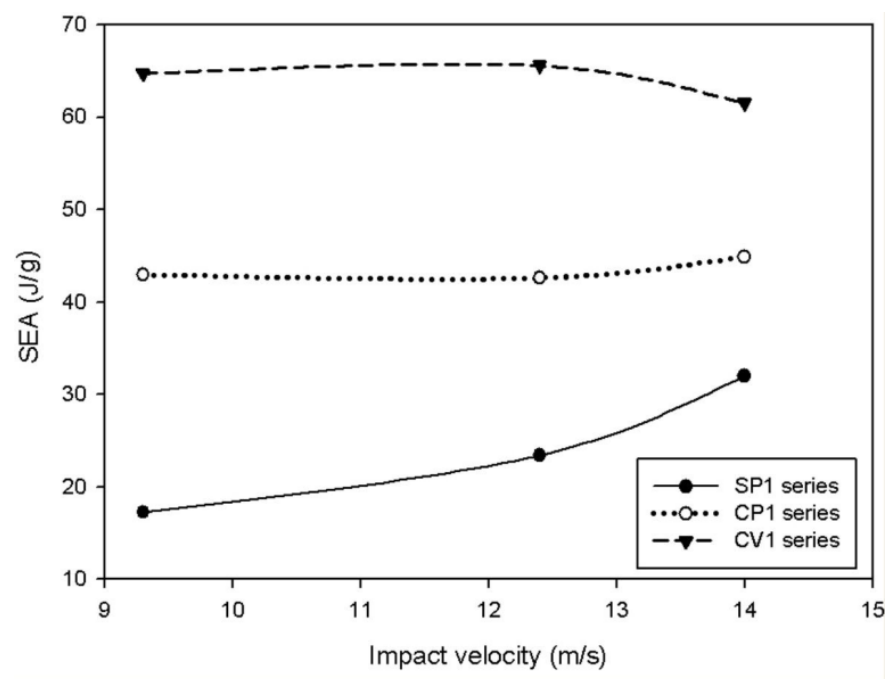

Figure 21: Effect of strain rate on SEA.

\section{Conclusions}

In this study, the impact energy absorption characteristics and the crushing mechanism using glass fibre/polyester and glass fibre/vinylester square and circular tubes with different thicknesses were investigated. The different $\mathrm{t} / / \mathrm{D}$ ratio and linear densities were chosen to achieve progressive failure of the tubes. The effect of tube geometry, triggering, strain rate and the type of resin on the specific energy absorption was studied. From the experimental results obtained for three impact velocities it can be concluded that:

- In all cases, the circular tube was found to absorb more energy than the square tubes. For different impact velocities $(9.3,12.4$ and $14 \mathrm{~m} / \mathrm{s})$, the circular tubes with t/D ratio of 0.06 yielded approximately $59 \%, 45 \%$ and $28 \%$ increase in SEA compared to the square tube with $\mathrm{t} / \mathrm{W}$ ratio of 0.075 . The increase in SEA of the circular tube was due to the geometry of the tube which controls the deceleration of the impactor by progressive crushing.

- $\quad$ Out of the two types of triggering, the type 1 ( $45^{\circ}$ chamfering around the edge of the tube) absorbed more energy than the type 2 (tulip pattern). In the case of circular tubes, due to triggering type 1, an increase in SEA of 7 to 9\% was observed. The increase in SEA was explained by the uniform circumferential delamination followed by the axial cracks of the tubes. However, in the case of square tubes, there was a negative effect observed due to triggering type 1 . The triggering type 2 showed $16.5 \%$ increase in SEA compared to triggering type1. This is due to the fact that, in the case of square tubes, a significant amount of energy was absorbed by lamina bending followed by the shear fracture of the fibres. The lower laminate stiffness of triggering type 2 enhanced above said failure modes.

- $\quad$ The SEA of the square tube was found to be strain rate sensitive. A $26 \%$ increase in SEA was seen with increasing impact velocities. However, in the case of circular tubes (made with glass polyester and glass vinylester) there was no significant increase in SEA with increasing impact velocities.

- $\quad$ Finally, studies of the glass polyester and glass vinylester tubes showed that tubes made of glass vinylester absorbed more energy ( SEA of 33 to $27 \%$ ) than the glass polyester tubes. The increase in SEA was due to the better interlaminar strength, higher strain to failure of vinylester resin and the blockage of inner material due to the smaller diameter of the tube.

* Sivakumar Palanivelu, Tel: +32-(0)9-264.33.15, Fax: +32-(0)9-264.35.87 


\section{Acknowledgements}

The authors gratefully acknowledge the financial support of the "Fund for Scientific Research" - Flanders (F.W.O) (Grant No: B-07674-03). The authors also wish to thank Luc Van Den Broecke for his assistance in conducting the impact experiments.

\section{References}

1. L Peroni M Avalle, V Petrella \& G Monacelli, Strain-rate effects on the energy absorption capability of crash boxes with different geometry. Structures under SHOCK AND IMPACT. 11(2002): pp. 259-268.

2. Langseth M., Hopperstad O. S. and Berstad T., Crashworthiness of aluminium extrusions: validation of numerical simulation, effect of mass ratio and impact velocity. International Journal of Impact Engineering. 22(1999): pp. 829-854.

3. Qiao J. S., Chen J. H. and Che H. Y., Crashworthiness assessment of square aluminum extrusions considering the damage evolution. Thin-Walled Structures. 44(2006): pp. 692-700.

4. Mamalis A. G., Robinson M., Manolakos D. E., Demosthenous G. A., Ioannidis M. B. and Carruthers J., Crashworthy capability of composite material structures. Composite Structures. 37(1997): pp. 109-134.

5. Ramakrishna S., Microstructural design of composite materials for crashworthy structural applications. Materials \& Design. 18(1997): pp. 167-173.

6. Farely G. L, Energy absorption in composite materials Journal of Composite Materials. 17(1983): pp. 167.

7. Hamada H., Coppola J. C., Hull D., Maekawa Z. and Sato H., Comparison of energy absorption of carbon/epoxy and carbon/PEEK composite tubes. Composites. 23(1992): pp. 245-252.

8. Fairfull A.H. \& Hull, D., Effect of specimen dimensions on the specific energy absorption of fibre composite tubes. In Proceedings of ICCM-VI,(1987): pp. 3.363.45 .

9. Farely G. L, Effect of specimen geometry on the energy absorption of composite materials. Journal of Composite Materials. 20(1986): pp. 390.

10. Solaimurugan S. and Velmurugan R., Progressive crushing of stitched glass/polyester composite cylindrical shells. Composites Science and Technology. 67(2007): pp. 422437.

11. Mamalis A. G., Manolakos D. E., Demosthenous G. A. and Ioannidis M. B., Energy absorption capability of fibreglass composite square frusta subjected to static and dynamic axial collapse. Thin-Walled Structures. 25(1996): pp. 269-295.

12. Solaimurugan S. and Velmurugan R., Influence of fibre orientation and stacking sequence on petalling of glass/polyester composite cylindrical shells under axial compression. International Journal of Solids and Structures. In Press, Corrected Proof.

13. Thronton P.H Energy absorption in composite structures. Journal of Composite Materials. 13(1979).

14. Jimenez M. A., Miravete A., Larrode E. and Revuelta D., Effect of trigger geometry on energy absorption in composite profiles. Composite Structures. 48(2000): pp. 107111.

* Sivakumar Palanivelu, Tel: +32-(0)9-264.33.15, Fax: +32-(0)9-264.35.87

Email: Sivakumar.Palanivelu@UGent.be 
15. Thornton P. H., The crush behavior of pultruded tubes at high strain rates. Journal of Composite Materials. 24(1989): pp. 22.

16. Mamalis A. G., Manolakos D. E., Ioannidis M. B. and Papapostolou D. P., On the response of thin-walled CFRP composite tubular components subjected to static and dynamic axial compressive loading: experimental. Composite Structures. 69(2005): pp. 407-420.

17. Hamada H., Kameo K., Sakaguchi M., Saito H. and Iwamoto M., Energy-absorption properties of braided composite rods. Composites Science and Technology. 60(2000): pp. 723-729.

18. Farely G. L, The effect of crushing speed on the energy-absorption capability of composite tubes. Journal of Composite Materials. 25(1991): pp. 1314.

19. Warrior N. A., Turner T. A., Robitaille F. and Rudd C. D., Effect of resin properties and processing parameters on crash energy absorbing composite structures made by RTM. Composites Part A: Applied Science and Manufacturing. 34(2003): pp. 543550.

20. Farely G. L, Effect of fibre and matrix maximum strain rate on the energy absorption of composite materials. Journal of Composite Materials. 20(1986): pp. 322.

21. Hamada H. and Ramakrishna S., Scaling effects in the energy absorption of carbonfiber/PEEK composite tubes. Composites Science and Technology. 55(1995): pp. 211-221.

22. Thronton P.H \& Edwards, P.J, Energy absorption in composite tubes. Journal of Composite Matter. 16(1982): pp. 521-545.

23. S Palanivelu R Verhelst, W V Paepegem, J Degrieck, D Kakogiannis, D V Hemelrijck, J Wastiels, K D Wolf and J Vontomme, Experimental and numerical study on axial crushing behaviour of pultruded composite tubes. Proceeding of the 13th European conference on composite materials, Stockholm, Sweden, June 25,(2008).

24. S.Palanivelu S. De Pauw, W.V.Paepegem, J.Degrieck, J.V.Ackeren, D.Kakogiannis, J.Watiels, D.V.Hemelrijck, K.D.Wolf and J.Vontomme, Validation of digitial image correlation technique for impact loading applications. Proceedings of 9th International conference on the Mechanical and Physical Behaviour of Materials under Dynamic Loading, Brussels, Belgium, September 7-11.,(2009).

25. Mamalis A. G., Manolakos D. E., Ioannidis M. B. and Papapostolou D. P., The static and dynamic axial collapse of CFRP square tubes: Finite element modelling. Composite Structures. 74(2006): pp. 213-225.

26. Mamalis A. G., Manolakos D. E., Demosthenous G. A. and Ioannidis M. B., The static and dynamic axial crumbling of thin-walled fibreglass composite square tubes. Composites Part B: Engineering. 28(1997): pp. 439-451. 